\title{
Gestão dos Recursos Hídricos e Cobrança pelo Uso da Água: Visão da Sociedade da Bacia Hidrográfica do Rio Santa Maria/RS
}

\author{
Francisco Rossarolla Forgiarini, Geraldo Lopes da Silveira, Jussara Cabral Cruz \\ Departamento de Hidráulica e Saneamento - CT/UFSM - Santa Maria, RS \\ francisco.rf@mail.ufsm.br, geraldo@ct.ufsm.br
}

Recebido: 10/07/06 - Revisado: 25/09/06 - Aceito: 06/02/07

\begin{abstract}
RESUMO
No Brasil, o novo modelo de gerenciamento dos recursos hídricos caracteriza-se pela gestão descentralizada com participação do poder público, dos usuários e da sociedade. O Sistema Nacional de Gerenciamento dos Recursos Hídricos (SNGRH) ainda está em fase de articulação e inúmeros questionamentos impedem a sua operacionalização, sendo que as principais dúvidas recaem sobre o instrumento de gestão cobrança pelo uso da água. Desta forma, o objetivo deste artigo é avaliar o conhecimento sobre a gestão dos recursos hídricos na bacia hidrográfica do rio Santa Maria/RS, que apresenta o uso da água preponderante a irrigação de arroz, com ênfase sobre a cobrança pelo uso da água. Por critério estatístico, foram aplicados 384 questionários para a população de aproximadamente 200.000 habitantes com questões que abordaram assuntos sobre os usos da água; sobre o comitê de bacia; e sobre a cobrança pelo uso da água. A pesquisa demonstrou que, quando comparado com os resultados obtidos para o Brasil, a população da bacia apresenta um maior conhecimento do SNGRH. Além disso, de um modo geral, a população se mostrou favorável à cobrança com os objetivos preconizados nas legislações brasileiras. O comitê de bacia hidrográfica do rio Santa Maria é um dos mais avançados e atuantes no Estado do Rio Grande do Sul, desempenhando suas funções desde 1994. Entretanto, para tornar-se uma verdadeira ferramenta de articulação dos interesses da bacia e um instrumento de desenvolvimento local é preciso que a sociedade assuma definitivamente a bacia hidrográfica como unidade de gestão e o comitê como o fórum de encaminhamento dos pleitos setoriais para o desenvolvimento regional integrado.
\end{abstract}

Palavras-chave: gestão dos recursos hídricos, cobrança pelo uso da água, bacia do rio Santa Maria.

\section{INTRODUÇÃO}

Ao longo da década de 1990 no Brasil, a União e a maioria dos Estados aprovaram leis que causaram a mudança do paradigma da gestão dos recursos hídricos. As alterações introduzidas nos marcos legais incorporaram novos fundamentos, dos quais se destacam o princípio da descentralização na política de recursos hídricos, adotando a bacia hidrográfica como unidade territorial de gestão, e a visão da água como um recurso natural limitado, dotado de valor econômico.

Conforme Thomas (2002), o velho paradigma de gestão dos recursos hídricos se caracterizou principalmente por uma gestão setorial e centralizada. Setorial porque, dentre outros fatores, privilegiou o setor elétrico em detrimento dos outros setores e, centralizada porque o planejamento, a alocação de recursos e a tomada de decisões relacionadas aos recursos hídricos eram controlados por agências federais ou estaduais, onde a prioridade era dada a grandes usuários públicos.

Em contrapartida, o novo Sistema Nacional de Gestão dos Recursos Hídricos (SNGRH) em implementação no país requer negociações entre órgãos de diferentes esferas do governo (federal, estadual e local), usuários e a sociedade civil organizada. Além disso, o processo de negociação ocorre na bacia hidrográfica, por meio de comitês de bacia que deliberam sobre as atividades e políticas públicas que possam afetar a quantidade e a qualidade das águas em suas circunscrições. De acordo com Pereira e Formiga-Johnsson (2005), a descentralização na política de recursos hídricos significa a institucionalização, em escala de bacia hidrográfica, de condições institucionais, técnicas, financeiras e organizacionais para a implementação das tarefas de gestão, conforme atribuições designadas nas leis de recursos hídricos.

O segundo importante fundamento, a visão da água como um bem econômico, foi introduzido quando se instituiu a cobrança pelo uso da água. 
Segundo Pearce e Turner (1990), a aplicação de instrumentos econômicos na política de gerenciamento dos recursos hídricos tem por princípio, principalmente, servir de incentivo financeiro para a mudança dos padrões de consumo dos usuários.

Utilizada como um instrumento de gestão, a cobrança deve arrecadar recursos para dar suporte financeiro ao SNGRH e às ações definidas pelos planos de bacia hidrográfica. Além disso, a cobrança deve indicar para a sociedade que a água é um bem escasso e que possui um valor, com a finalidade de que este recurso seja utilizado de forma racional e que o seu uso atenda aos princípios do desenvolvimento sustentável.

No Brasil, o SNGRH ainda está em fase de articulação e inúmeros questionamentos impedem a sua operacionalização. Pereira e Speziali (2005) enfatizam que as principais dúvidas recaem sobre o instrumento de gestão cobrança pelo uso da água e questões como quanto cobrar; de quem cobrar; e quais impactos serão causados nas relações econômicas, sociais e políticas devem ser respondidas antes da implementação do sistema.

Além disso, de acordo com IBOPE/WWFBrasil (2005), a sociedade brasileira não conhece os mecanismos de participação que estão à sua disposição na defesa das bacias hidrográficas. Os resultados obtidos pela pesquisa encomendada pelo Programa Água para a Vida, do WWF-Brasil, ao Instituto Brasileiro de Pesquisa de Opinião Pública e Estatística (IBOPE), evidenciam a necessidade de desenvolver trabalhos com foco sobre a sociedade brasileira.

Assim, o presente trabalho tem como objetivo avaliar o conhecimento sobre a gestão dos recursos hídricos em uma bacia hidrográfica brasileira, com ênfase sobre a cobrança pelo uso da água. A partir da metodologia empregada e dos resultados obtidos pretende-se fornecer informações aos demais comitês de bacia brasileiros e ao comitê de gerenciamento da bacia estudada que possibilitem identificar estratégias de gerenciamento com objetivo de facilitar a implementação do SNGRH na sua área de atuação.

\section{METODOLOGIA}

\section{Bacia de estudo}

O local onde foi desenvolvido o estudo é a bacia do rio Santa Maria, situada na fronteira sudoeste do Rio Grande do Sul (Figura 1), abrangendo uma área em torno de $15.754 \mathrm{~km}^{2}$. Na bacia localizam-se seis municípios: Santana do Livramento;
Dom Pedrito; Lavras do Sul; Rosário do Sul; Cacequi; e São Gabriel. Segundo IBGE (2000), a população total é de 257.745 habitantes, 11,78\% dela localizada na zona rural e $88,22 \%$ na zona urbana. Entretanto, a população residente é de aproximadamente 200.000, uma vez que as sedes dos municípios de São Gabriel e Lavras do Sul situam-se fora da bacia.

A atividade econômica preponderante na região é a agropecuária, desenvolvida nas paisagens típicas da fronteira gaúcha. A pecuária extensiva tradicional se mescla com a orizicultura moderna, em campos entremeados com várzeas ocupadas por rotação de pastagem natural e lavoura de arroz. Esta paisagem apresenta um eixo de mudanças LesteOeste, que reflete as diferenças de uso da terra, em função da transição entre o Escudo SulRiograndense, a Depressão Central e o Planalto Meridional (Campanha Gaúcha).

O setor agrícola é o maior usuário de água, seguido do setor de abastecimento humano e da pecuária. Nos períodos de irrigação, a região de estudo apresenta escassez hídrica gerando sérios conflitos de uso, principalmente entre os setores da agricultura e do abastecimento humano.

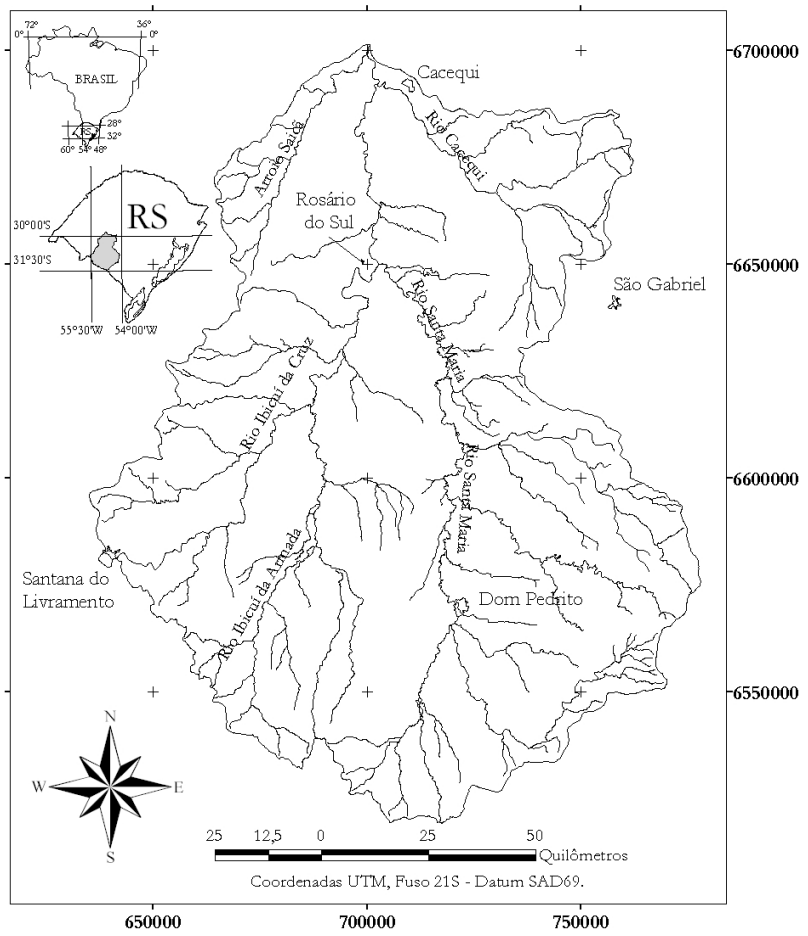

Figura 1 - Situação e localização da bacia hidrográfica do rio Santa Maria. 
O Comitê de Gerenciamento da Bacia do rio Santa Maria se constitui, juntamente com o Comitê da Bacia do rio dos Sinos e o Comitê da Bacia do rio Gravataí, em uma das primeiras experiências no Estado de aplicação de mecanismos de gestão. $\mathrm{O}$ comitê foi criado com a edição do Decreto Estadual n⿳⺈ 35.103, de maio de 1994.

A bacia do rio Santa Maria é uma das bacias mais avançadas na realização de estudos para a operacionalização dos instrumentos de gestão dos recursos hídricos no Estado do Rio Grande do Sul. Desde a implantação do comitê os seguintes instrumentos de gestão já foram estudados:

I. Enquadramento dos recursos hídricos (FEPAM, 2001);

II. Outorga para uso da água (UFSM/SEMA, 2004a);

III. Cobrança pelo uso da água (Balarine et al., 2000 e UFSM/SEMA, 2004b).

O Plano de Bacia ainda não possui um estudo específico. Entretanto, o Departamento de Recursos Hídricos do Estado está elaborando um Termo de Referência para a realização do Plano, que será baseado em EUROESTUDIOS e NOVOTECNI (2003).

O único instrumento de gestão que ainda não possui nenhum estudo desenvolvido é o Sistema de Informação. Entretanto, o Comitê possui um site na internet (http://www.comites antamaria. com. $\mathrm{br} /$ ) que funciona parcialmente como tal, informando a comunidade sobre o que é discutido nas reuniões ordinárias do comitê e sobre o andamento dos estudos que estão sendo desenvolvidos.

\section{Pesquisa de opinião pública}

O conhecimento sobre a gestão dos recursos hídricos na bacia hidrográfica do rio Santa Maria foi avaliado por meio da aplicação de questionários aos seus habitantes. Pretendeu-se avaliar o nível de conhecimento do SNGRH pela sociedade, uma vez que a participação social possui um papel fundamental na aplicação da PNRH, influenciando a tomada de decisões. A pesquisa foi realizada apenas nos municípios com sede dentro da bacia por uma questão operacional, não sendo aplicados questionários na zona rural. A população urbana representa aproximadamente $90 \%$ da população da região de estudo.

O tipo de amostragem adotada foi a amostragem estratificada proporcional, segundo a população percentual de cada município. Este procedi- mento foi adotado uma vez que cada município representa um estrato mais homogêneo que a população total da bacia, pois apresentam realidades diferentes quanto ao conhecimento do SNGRH e ao abastecimento e disponibilidade de água.

Conforme Ethur et al. (2002), quando no problema de estudo são identificados estratos, uma amostra obtida por meio do processo de amostragem estratificada proporcional tende a gerar resultados mais precisos quando comparada com uma amostra aleatória simples. Então, sobre os estratos (municípios) da população, foram realizadas seleções aleatórias de forma independente e a amostra completa foi obtida por meio da agregação das amostras de cada município. A amostra foi calculada utilizando a Equação 1 (Ethur et al., 2002), dada por:

$$
n=\frac{\left(z_{\alpha / 2}\right)^{2} p^{*} q^{*} N}{e_{o}^{2}(N-1)+\left(z_{\alpha / 2}\right)^{2} p^{*} q^{*}} .
$$

O estudo considerou: população $(\mathrm{N})$ maior de 16 anos, aproximadamente de 156.000 habitantes; grau de confiança de $95 \%\left(\mathrm{Z}_{\alpha / 2}=1,96\right)$; erro amostral $\left(\mathrm{e}_{\mathrm{o}}\right)$ de 5\%; proporção amostral ( $\left.\mathrm{p}^{*}\right)$ de $50 \%\left(\operatorname{logo}, \mathrm{q}^{*}=50 \%\right.$, uma vez que $\mathrm{p}^{*}+\mathrm{q}^{*}=1$, $\mathrm{q}^{*}$ é o complemento da proporção amostral); chegando-se a uma amostra (n) de 384 pessoas. Foram aplicadas 18 perguntas com respostas fechadas, de múltipla escolha, separadas quanto à:

(i) uso e consumo de água:

1. O que você acha do consumo de água realizado por você nas suas atividades diárias?

2. Qual das medidas abaixo você estaria disposto a adotar para evitar que exista a falta de água?

3. Em sua opinião, existem conflitos (falta de água para um setor enquanto há água para outro) entre os setores usuários da região?

4. Você acredita que a região enfrentará problemas com a falta de água?

(ii) comitê de gerenciamento da bacia:

5. Quem você acredita que são os responsáveis pelas decisões relativas aos usos da água na região?

6. Você sabe o que é ou conhece o comitê da bacia hidrográfica do Rio Santa Maria?

7. Como você conheceu o comitê? 
8. Você tem conhecimento de alguém que participa do comitê?

9. Você conhece as funções de um comitê de bacia hidrográfica?

10. Você conhece o seu representante dentro do Comitê?

11. Como você avalia a participação da comunidade nas definições do Comitê?

\section{(iii) cobrança pelo uso da água:}

12. Você já ouviu falar da cobrança pelo uso da água? (Não é o valor pago pela prestação do serviço de abastecimento água e tratamento de esgoto).

13. Para você, o que é a cobrança pelo uso da água?

14. Você é favorável à cobrança pelo uso da água para investir em obras na região e induzir o uso racional?

15. Caso a resposta à pergunta 14 seja "Sim", qual seria a sua disposição a pagar (DAP)?

16. Para você, qual será o principal efeito da cobrança?

17. Para você, o investimento em obras para a gestão da água deve ser atribuição de quem?

18. Caso existisse um fundo para financiamento de obras na região, para qual setor dos listados abaixo você priorizaria os investimentos?

Algumas respostas foram comparadas com os resultados da pesquisa do Programa Água para a Vida, do WWF-Brasil, encomendada junto ao IBOPE em 2005.

Devido ao desconhecimento do uso da palavra "conflito" em recursos hídricos, na pergunta 3 procurou-se deixar claro introduzindo o texto "falta de água para um setor enquanto há água para outro". Na pergunta 12, para evitar a confusão com a tarifa cobrada pelo serviço de abastecimento de água e tratamento de esgoto já pagos pelos usuários, foi incluído um texto explicando que o tema da pergunta não se tratava desta tarifa.

As perguntas 7 a 11 foram aplicadas somente aos entrevistados que responderam positivamente à pergunta 6 , ou seja, sabem o que é ou conhecem o comitê da bacia hidrográfica do Rio Santa Maria. A pergunta 15 procurou identificar uma estimativa preliminar da DAP da população. Para uma análise mais detalhada, deveria ser utilizado um método mais sofisticado, como por exemplo, o Método de Valoração Contingente (MVC).
Segundo Faria e Nogueira (1998), a idéia básica do MVC é que as pessoas possuem diferentes graus de preferências, gostos ou necessidades por diferentes bens e serviços e isso se manifesta quando elas vão ao mercado e pagam quantias específicas por eles. De acordo com os autores, este método busca valorar bens públicos e/ou ambientais para os quais não há preços de mercado. O MVC se propõe, por meio se surveys, revelar as preferências do consumidor por um bem ou serviço ambiental e, com isso, captar a sua DAP. Trata-se, portanto, da criação de um mercado hipotético, construído a partir de técnicas de questionários que buscam revelar as preferências dos indivíduos pelo bem público ou ambiental.

Tabela 1 - Perfil da amostra: distribuição por sexo, município, idade, escolaridade e renda.

\begin{tabular}{|c|c|c|}
\hline $\begin{array}{l}\text { Distribui- } \\
\text { ção }\end{array}$ & Categoria & $\begin{array}{l}\begin{array}{l}\text { Porcenta- } \\
\text { gem }\end{array} \\
\end{array}$ \\
\hline \multirow{2}{*}{ Sexo } & Masculino & $52,08 \%$ \\
\hline & Feminino & $47,92 \%$ \\
\hline \multirow{4}{*}{ Município } & Cacequi & $7,55 \%$ \\
\hline & Dom Pedrito & $22,14 \%$ \\
\hline & Rosário do Sul & $21,35 \%$ \\
\hline & Santana do Livramento & $48,96 \%$ \\
\hline \multirow{6}{*}{ Idade } & 16 a 20 & $8,59 \%$ \\
\hline & 21 a 30 & $31,25 \%$ \\
\hline & 31 a 40 & $25,00 \%$ \\
\hline & 41 a 50 & $19,01 \%$ \\
\hline & 51 a 65 & $11,98 \%$ \\
\hline & mais de 65 & $4,17 \%$ \\
\hline \multirow{4}{*}{$\begin{array}{l}\text { Escolari- } \\
\text { dade }\end{array}$} & $1^{\circ} \mathrm{Grau}$ Incompleto & $8,59 \%$ \\
\hline & $1^{\circ} \mathrm{Grau}$ Completo & $11,72 \%$ \\
\hline & $\begin{array}{lrl}2^{\circ} \text { Grau } & \text { Incom. ou } \\
\text { Completo } & \end{array}$ & $57,29 \%$ \\
\hline & $\begin{array}{l}\text { Superior Incompleto e } \\
\text { mais }\end{array}$ & $22,40 \%$ \\
\hline \multirow{6}{*}{ Renda } & Até $01 \mathrm{SM}$ & $7,81 \%$ \\
\hline & De 01 a 02 SM & $12,24 \%$ \\
\hline & De 02 a $03 \mathrm{SM}$ & $20,05 \%$ \\
\hline & De 03 a 05 SM & $23,44 \%$ \\
\hline & De 05 a $10 \mathrm{SM}$ & $26,82 \%$ \\
\hline & 10 ou mais SM & $9,64 \%$ \\
\hline
\end{tabular}

De acordo com Turner (1994), existem diversas formas de calcular a DAP por meio da aplicação de questionários, como por exemplo, (i) openended; (ii) bidding game; (iii) modelo de referendo; dentre outras. $\mathrm{O}$ autor enfatiza que após a aplicação dos questionários, os resultados devem ser tabulados e submetidos a uma análise econométrica 
para se determinar valores médios de DAP. A partir dos resultados preliminares obtidos, poderá ser desenvolvido um estudo especifico para se determinar a DAP.

\section{RESULTADOS E DISCUSSÃO}

O perfil da amostra é apresentado na Tabela 1.

\section{Perguntas quanto ao uso e consumo de água}

Conforme se observa na Figura 2, em todos os municípios os resultados demonstram que a população acredita estar consumindo água de maneira ideal. Dom Pedrito é o município que apresenta os principais problemas de disponibilidade de água, chegando, em época de irrigação, a serem implantados períodos de racionamento. Assim, os habitantes do município são forçados a utilizar a água de maneira racional, o que foi observado nos resultados obtidos.

No Brasil, $65 \%$ das pessoas acreditam que o consumo poderia ser menor e $34 \%$ disseram que o seu consumo está próximo do ideal (IBOPE/WWFBrasil, 2005). Na bacia hidrográfica do rio Santa Maria o resultado se inverteu, aproximadamente $66 \%$ acreditam que o seu consumo está próximo do ideal e $22 \%$ que o consumo poderia ser menor.

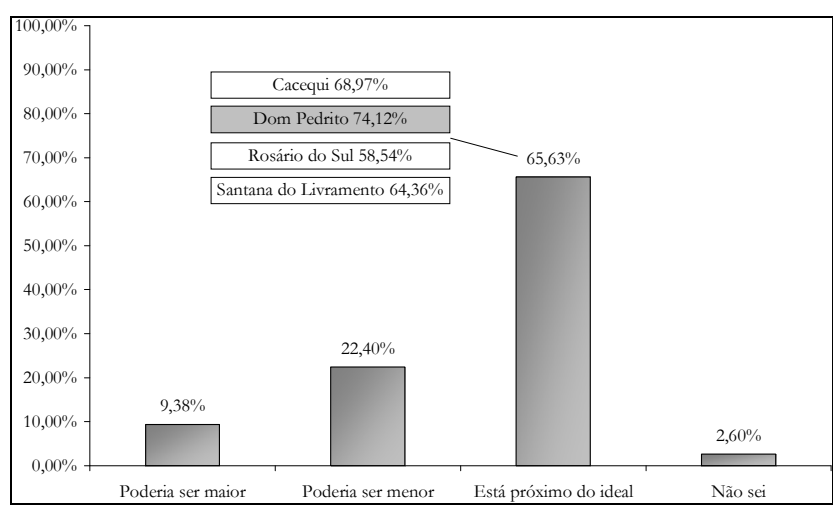

Figura 2 - Opinião da população da bacia do rio Santa Maria sobre o consumo de água.

A Figura 3 demonstra que em Cacequi a população está mais disposta a participar na tomada de decisões e a pagar pelo uso da água. Nos demais municípios, as pessoas utilizariam uma quantidade menor de água. O sexo masculino está mais disposto a participar das decisões, as mulheres preferem uti- lizar uma quantidade menor de água $(41,85 \%$ contra $30,50 \%$ dos homens). Nas faixas etárias mais avançadas se observou um menor percentual de respostas "pagar pelo uso da água", aproximadamente $6 \%$ contra $16 \%$. Além disso, o que se observou é que a principal medida a ser adotada por todos é a redução do consumo e participar de programas de educação ambiental.

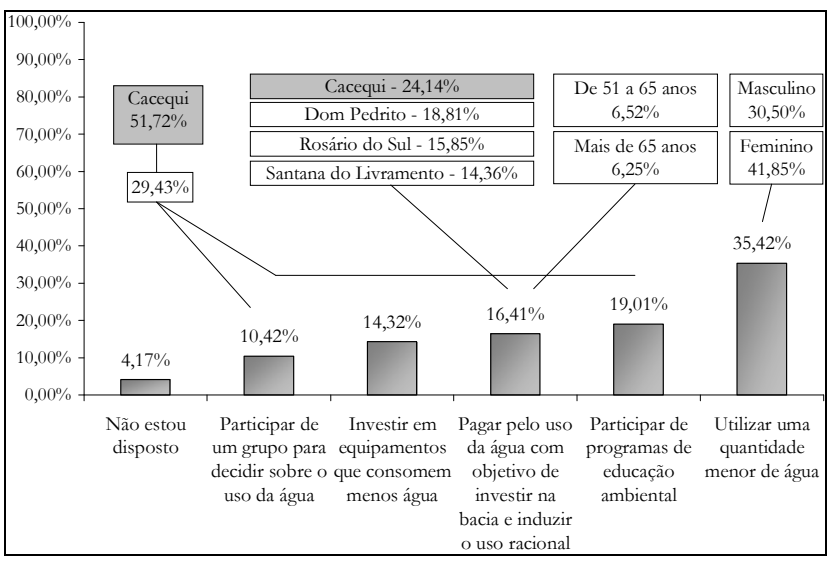

Figura 3 - Medidas que a população da bacia do rio Santa Maria estaria disposta a adotar para evitar que exista falta de água.

Conforme a Figura 4 observa-se que a população do município de Santana do Livramento apresenta menor conhecimento sobre os problemas da bacia, devido à cidade ser abastecida por um dos maiores mananciais subterrâneos do planeta, o Aqüífero Guarani. Além disso, observa-se que quanto maior a escolaridade maior o conhecimento sobre os conflitos.

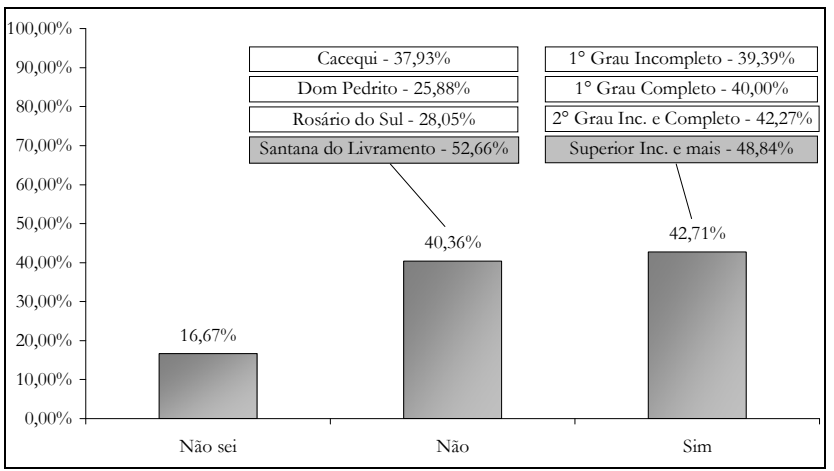

Figura 4 - Opinião da população da bacia do rio Santa Maria sobre a existência de conflitos entre usuários na região. 
Os municípios de Dom Pedrito e Rosário do Sul são os que mais sofrem com os problemas de falta de água em época de irrigação e, conseqüentemente, foram nestes municípios que se observaram respostas positivas quanto à existência de problemas com a falta de água (Figura 5). Aproximadamente $78 \%$ da população da bacia acreditam que a bacia já enfrenta ou enfrentará problemas com a falta de água (soma das respostas "Sim"). Este resultado é inferior aos obtidos para o Brasil, pois conforme IBOPE/WWF-Brasil (2005), 88\% da população brasileira acreditam que o Brasil terá problemas com o abastecimento de água no futuro.

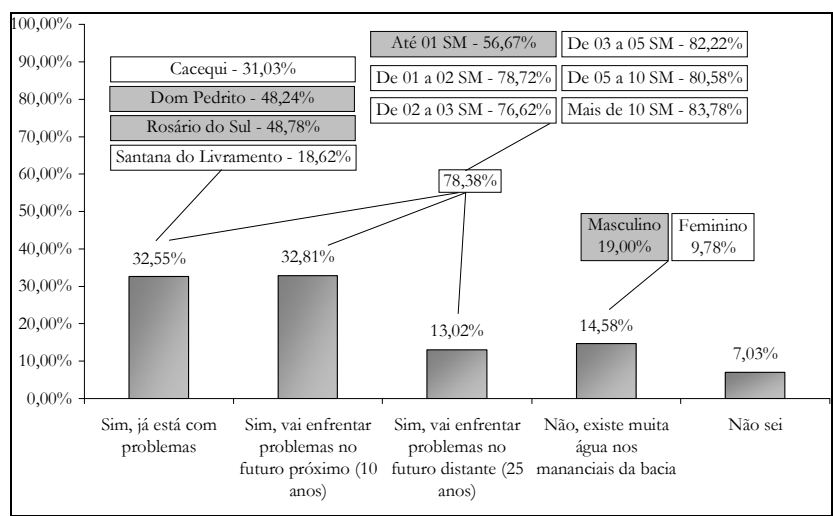

Figura 5 - Opinião da população da bacia do rio Santa Maria sobre a possibilidade de enfrentar problemas com a falta de água.

\section{Perguntas quanto ao comitê da bacia}

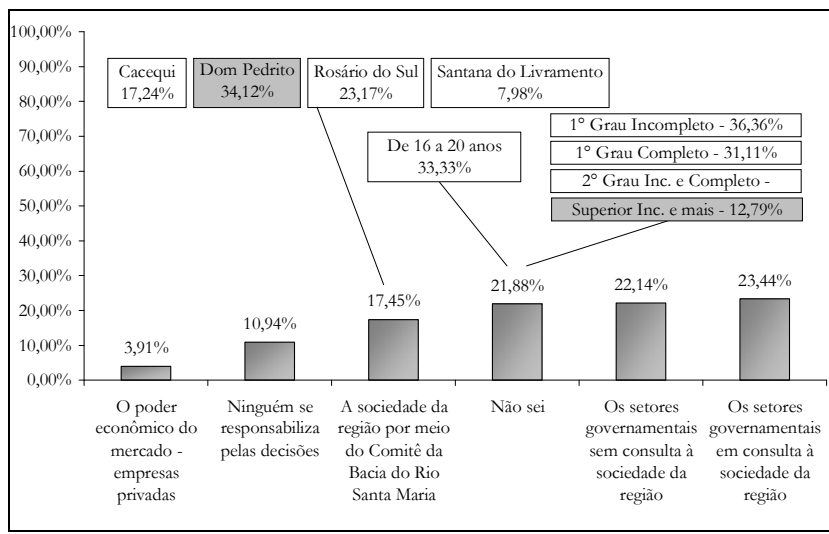

Figura 6 - Opinião da população da bacia do rio Santa Maria sobre os responsáveis pelas decisões relativas aos usos da água.

O maior conhecimento sobre a tomada de decisões relativas aos recursos hídricos é nos municípios de Dom Pedrito e Rosário do Sul (Figura 6).
Além disso, percebe-se que à medida que aumenta o grau de escolaridade aumenta o conhecimento dos responsáveis pelas decisões relativas aos usos da água.

A Figura 7 apresenta o resultado do conhecimento sobre o comitê de gerenciamento da bacia do rio Santa Maria, analisando-a, observa-se:

- Cerca de $40 \%$ da população conhece o comitê de gerenciamento da bacia hidrográfica do rio Santa Maria. De acordo com IBOPE/WWF-Brasil (2005), 29\% da população brasileira já ouviram falar dos comitês de bacia hidrográfica, e $70 \%$ nunca ouviram falar;

- Maior conhecimento sobre o comitê em Dom Pedrito e Rosário do Sul. No município de Santana do Livramento o conhecimento é de apenas 14,36\%;

- Maior conhecimento no grau de escolaridade Superior Incompleto e mais;

- O sexo masculino é que apresenta maior conhecimento e participação nas reuniões do comitê (cerca de 80\%). Segundo Projeto Marca D’água (2004), em geral, os comitês de bacia nacionais são compostos em sua grande maioria por homens e a participação mais efetiva nas discussões é do sexo masculino, resultados encontrados também na bacia do rio Santa Maria.

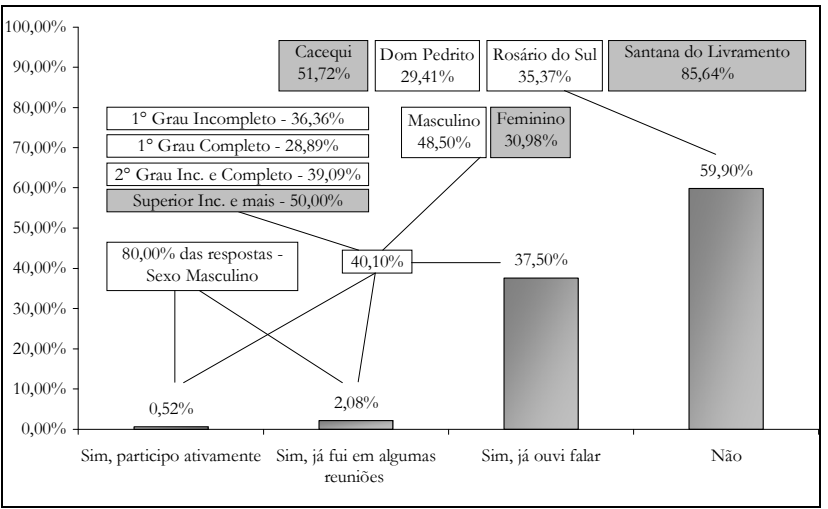

Figura 7 - Conhecimento da população sobre o comitê de gerenciamento da bacia do rio Santa Maria.

A Figura 8 demonstra que as pessoas conheceram o comitê principalmente por Jornais e Rádio. Esse resultado era esperado, pois a maioria das reuniões do comitê são transmitidas por uma rádio $\mathrm{AM}$ da região e, eventualmente, o comitê apresenta 
reportagens nos jornais de circulação nos municípios.

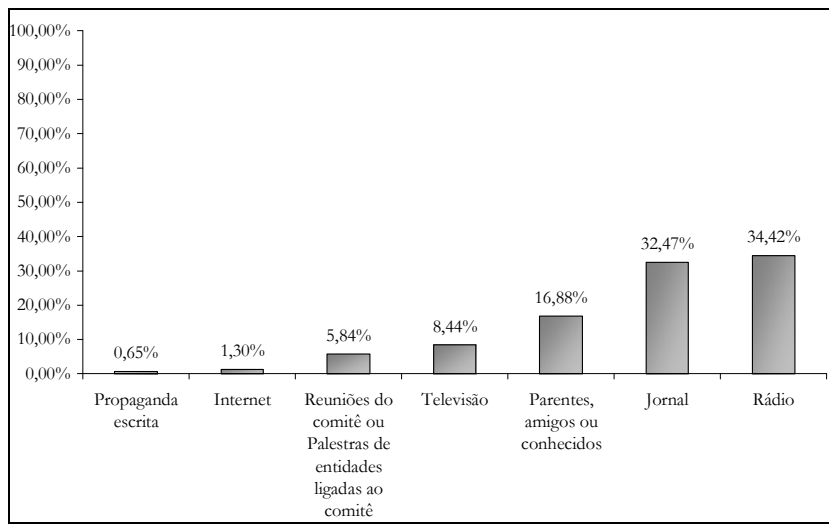

Figura 8 - Maneira como a população conheceu o comitê da bacia do rio Santa Maria.

As Figuras 9, 10 e 11 indicam a distância e a indiferença existente entre a população e o comitê (estas questões foram aplicadas somente para quem sabia o que é ou conhecia o comitê):

- Metade das pessoas não conhece nenhuma pessoa que participa do comitê;

- Aproximadamente $75 \%$ das pessoas que disseram conhecer o comitê não sabem qual a sua função;

- $\quad 71,43 \%$ não conhecem o seu representante dentro do comitê.

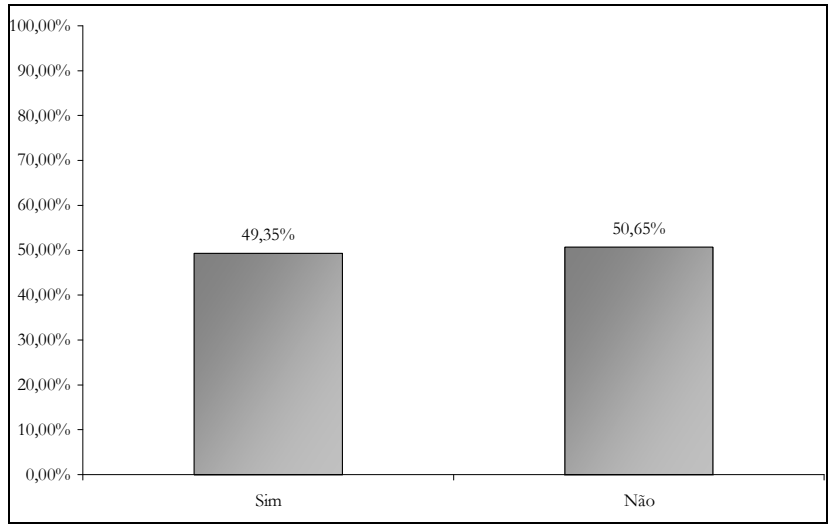

Figura 9 - Conhecimento da população de alguma pessoa que participa do comitê da bacia do rio Santa Maria.

Estes resultados confirmam as informações existentes no Projeto Marca D’Água (2004), que aponta a excessiva representatividade dos setores ligados à orizicultura em detrimento aos outros segmentos sociais. Dentro do comitê estão refletidas as características do poder local, o que tende a direcionar as ações e decisões do organismo aos interesses desses grupos. O Projeto Marca D'Água (2004) aponta que esta situação pode dever-se à falta de interesse dos outros segmentos sociais em participar, mas que, de qualquer forma, pode vir a questionar a natureza supostamente participativa do comitê da bacia do rio Santa Maria.

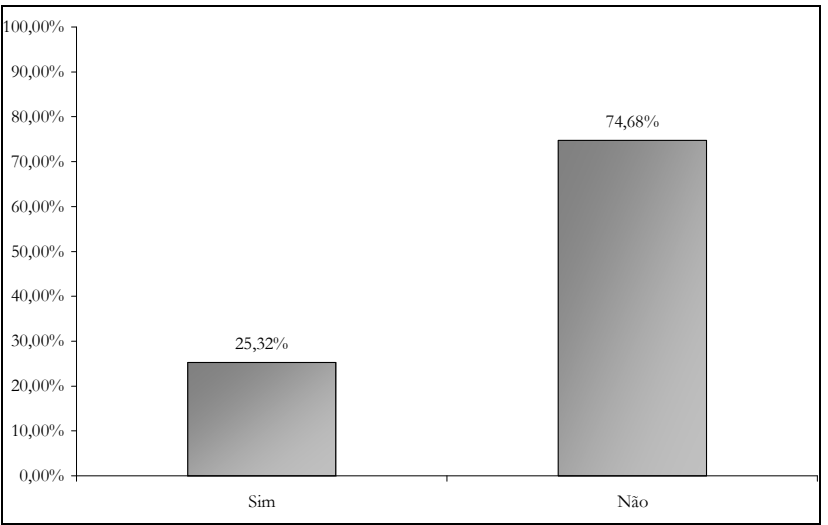

Figura 10 - Conhecimento da população sobre as funções do comitê da bacia do rio Santa Maria.

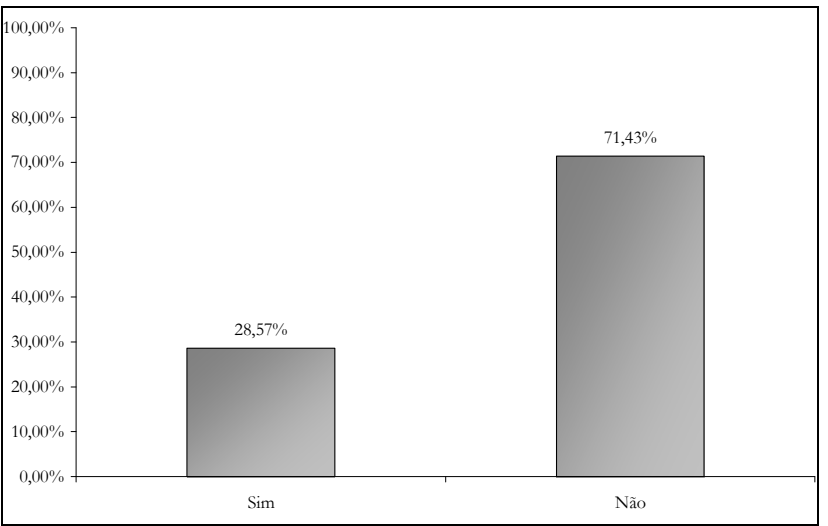

Figura 11 - Conhecimento da população sobre os seus representantes no comitê da bacia do rio Santa Maria.

Os resultados apresentados na Figura 12 demonstram que a população acredita que a sua participação nas decisões do comitê está entre "Boa" e "Ruim", com um maior número de respostas para "Regular" (31,82\%). Observa-se novamente a indiferença sobre o comitê, representado no grande número de respostas "Não sei" $(29,87 \%)$. 
Gestão dos Recursos Hídricos e Cobrança pelo Uso da Água: Visão da Sociedade da Bacia Hidrográfica do Rio Santa Maria/RS

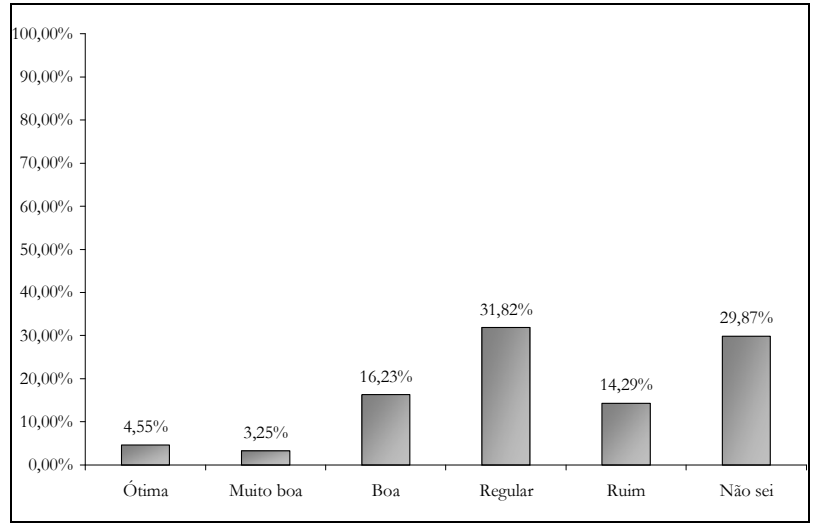

Figura 12 - Avaliação da participação da comunidade nas definições do comitê da bacia do rio Santa Maria.

\section{Perguntas quanto à cobrança pelo uso da água}

O menor conhecimento da cobrança pelo uso da água é no município de Santana do Livramento. Na bacia como um todo o conhecimento foi baixo também $(34,90 \%)$ e o maior conhecimento da cobrança é pelo sexo masculino.

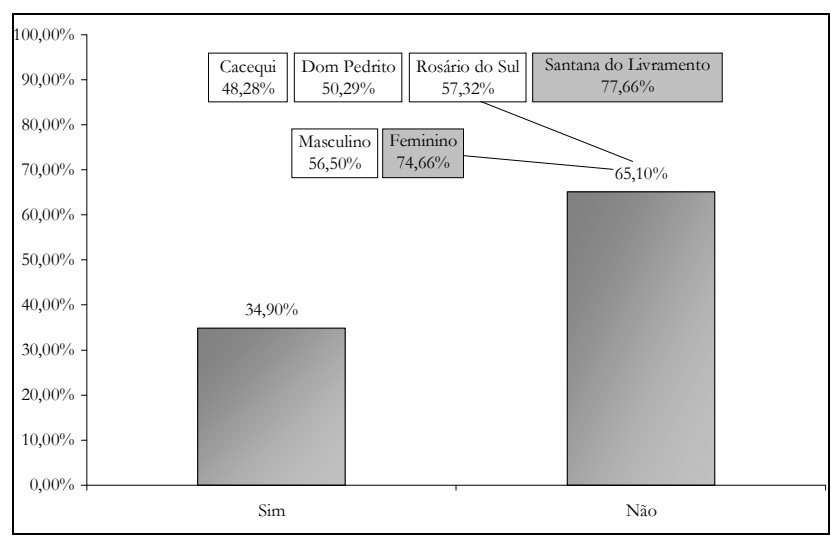

Figura 13 - Conhecimento da população sobre a cobrança pelo uso da água.

A maioria dos habitantes da bacia acredita que a cobrança será implementada pois a água é um bem público $(51,30 \%)$, uma parcela menor $(29,69 \%)$ respondeu que a cobrança é um novo imposto criado apenas com o objetivo de aumentar a receita do governo. $O$ maior conhecimento da motivação da cobrança é em Dom Pedrito, 64,71\% responderam que a cobrança será implementada pois a água é um bem público. A Figura 14 apresenta a opinião da população sobre o que é a cobrança pelo uso da água.

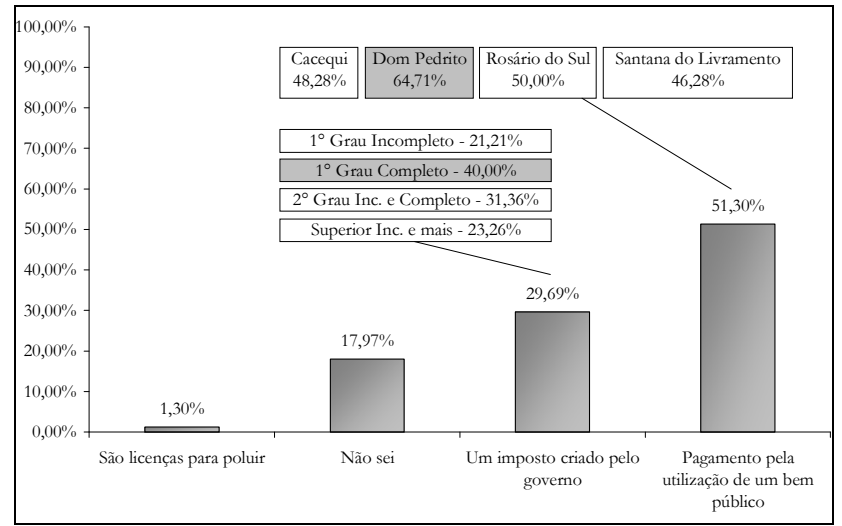

Figura 14 - Opinião da população sobre o que é a cobrança pelo uso da água.

A Figura 15 apresenta um resultado expressivo em Dom Pedrito, mesmo os habitantes do município tendo o maior conhecimento sobre a cobrança é a menos disposta a pagar com o objetivo de investir em obras na região (objetivo de financiamento) e induzir o uso racional (objetivo de gestão da demanda). De um modo geral, existe favorabilidade à cobrança segundo os objetivos descritos anteriormente $(56,51 \%)$. Segundo IBOPE/WWF-Brasil (2005), 74\% da população brasileira são favoráveis à cobrança pelo uso da água, $20 \%$ não são favoráveis e $6 \%$ não opinaram. Santa Maria:

Favorabilidade à cobrança na bacia do rio

- Maior favorabilidade à cobrança na faixa entre 16 e 20 anos;

- Quanto maior o grau de escolaridade menor a favorabilidade à cobrança;

- Quanto maior a renda menor a favorabilidade à cobrança.

A maioria dos habitantes não soube responder a sua DAP, escolhendo as alternativas "O suficiente para construir as obras definidas no Plano de Bacia" ou "Estou disposto a pagar mas não sei quanto" demonstrando a necessidade de realizar um trabalho específico para se determinar a DAP. Observou-se também na Figura 16 que a população deseja pagar o mínimo possível, isto está representado no resultado de $28,11 \%$ que assinalou a resposta " $1 \%$ do que pago na minha conta de água e esgoto". Novamente, observa-se que em Dom Pedrito a disposição é a mínima. 


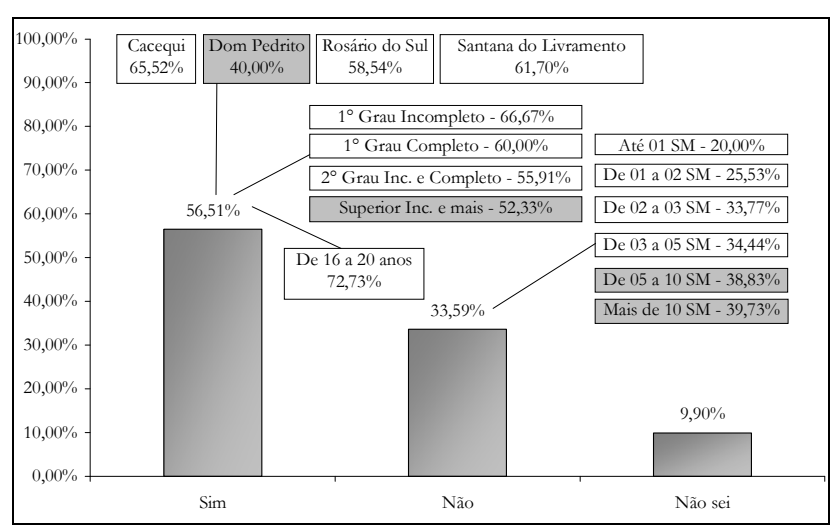

Figura 15 - Favorabilidade da cobrança pelo uso da água na bacia do rio Santa Maria

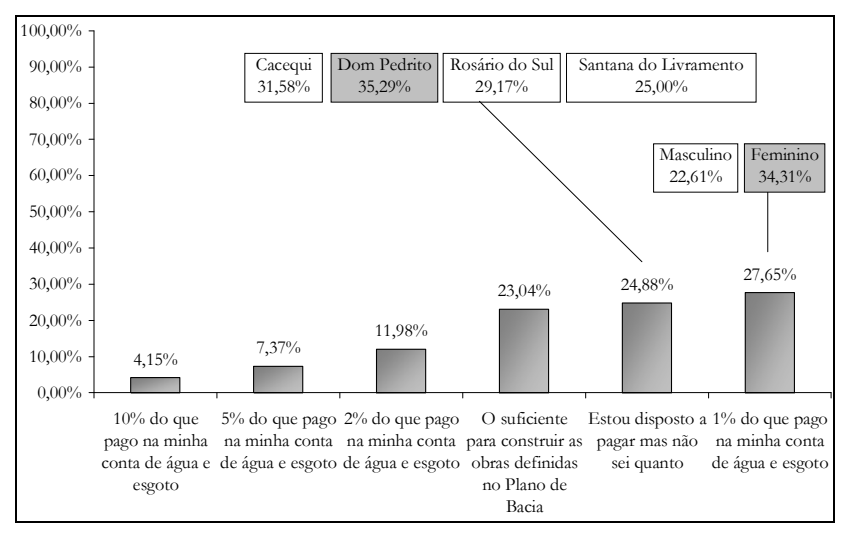

Figura 16 - Disposição a pagar (DAP) pelo uso da água na bacia do rio Santa Maria.

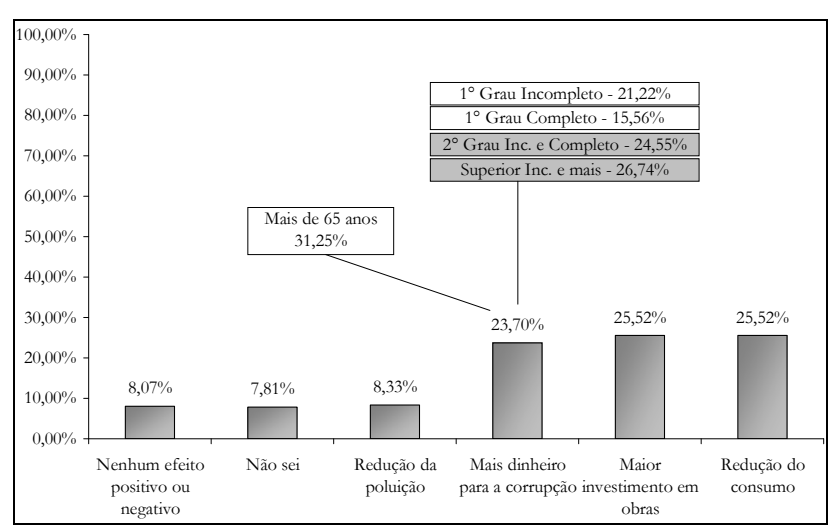

Figura 17 - Opinião da população da bacia do rio Santa Maria sobre o principal efeito da cobrança pelo uso da água.

A Figura 17 apresenta a opinião da população sobre o principal efeito da cobrança pelo uso da água. Os resultados mais encontrados foram a redução do consumo e o maior investimento em obras. Entretanto, boa parte acredita que o dinheiro da cobrança possa ser desviado para a corrupção devido a pouca credibilidade dos governantes e políticos do país, principalmente nos mais instruídos e nos mais velhos, justamente os menos favoráveis à cobrança.

A Figura 18 apresenta como resultado que os habitantes da bacia acreditam ser atribuição do Governo Federal, Estadual e Municipal o investimento em obras para a gestão da água (estações de tratamento de água e esgoto, barragens, canais, etc).

Apenas 18,75\% acreditam que seja atribuição dos usuários da água arrecadar fundos para financiar obras para a gestão das águas e este percentual diminui entre as pessoas com mais de 65 anos.

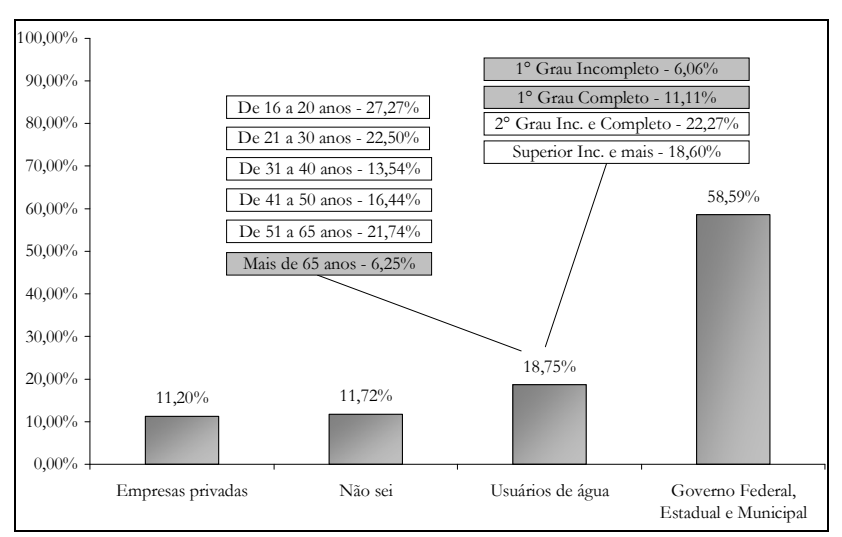

Figura 18 - Opinião da população da bacia do rio Santa Maria sobre a responsabilidade de investimentos em obras para a gestão das águas.

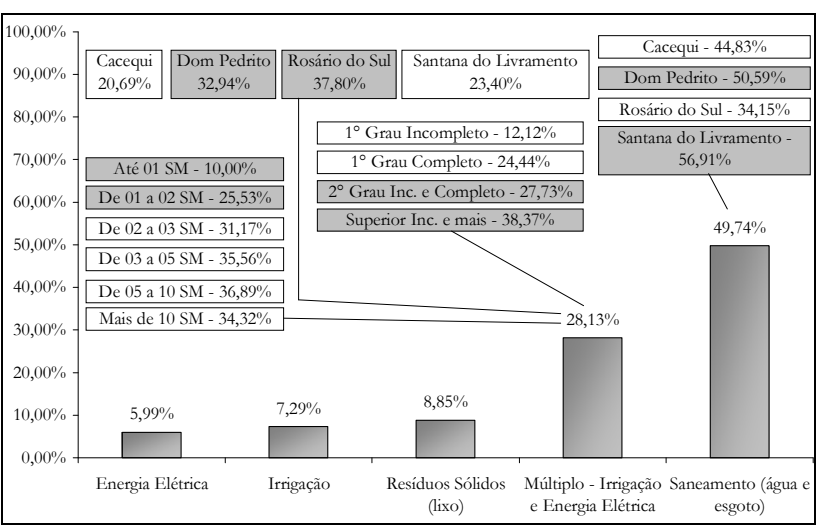

Figura 19 - Opinião da população da bacia do rio Santa Maria sobre o setor onde deveriam ser aplicados os recursos da cobrança pelo uso da água. 
A população quer maiores investimentos na área de Saneamento, conforme é observado na Figura 19. Em Dom Pedrito e Rosário do Sul se constatou que são desejados investimentos em Irrigação, desde que sejam aproveitadas as barragens para geração de energia elétrica. Os menos instruídos e com renda mais baixa preferem que os investimentos sejam realizados na área de saneamento (infraestrutura básica) enquanto os mais instruídos e com renda maior preferem que os investimentos sejam realizados em áreas que possibilitariam o crescimento econômico da região (Irrigação e Energia Elétrica).

\section{CONCLUSÕES}

A pesquisa demonstrou que, quando comparado com os resultados obtidos no Brasil, a população da bacia possui um conhecimento maior do SNGRH. Entretanto, os resultados indicaram que a população não conhece exatamente as funções do comitê e tão pouco os seus representantes dentro do comitê.

Os municípios da bacia apresentam realidades diferentes relativas ao abastecimento e oferta de água que foram refletidas nos resultados da pesquisa. Os municípios de Santana do Livramento e Cacequi, que sofrem menos com problemas de falta de água, apresentaram menor conhecimento à respeito dos conflitos existentes na região, dos problemas com falta de água e do comitê de gerenciamento da bacia. Em contrapartida, nos municípios de Dom Pedrito e Rosário do Sul, que apresentam constantes conflitos de uso da água, a população possui um maior conhecimento sobre o SNGRH e sobre a cobrança pelo uso da água.

Os resultados evidenciam que as pessoas do sexo masculino e com maior escolaridade possuem maior conhecimento quanto ao SNGRH. De um modo geral, os habitantes da bacia se mostraram favoráveis à cobrança com os objetivos preconizados nas legislações brasileiras. A maior favorabilidade à cobrança é entre os mais jovens e, quanto maior o grau de escolaridade e a renda, menor a favorabilidade à cobrança.

Aproximadamente $48 \%$ das pessoas não souberam responder a sua DAP, demonstrando a necessidade de aprofundar o estudo para obter uma melhor estimativa. A população acredita que a cobrança causará principalmente uma redução do consumo e maiores investimentos em obras. Entre- tanto, existe o temor que os recursos da cobrança possam ser desviados para usos indevidos.

O comitê da bacia hidrográfica do rio Santa Maria é um dos mais avançados e atuantes no Estado do Rio Grande do Sul, desempenhando suas funções desde 1994. Entretanto, salienta-se que é indispensável uma ampla divulgação e um trabalho de convencimento da sociedade quanto à importância da participação no comitê de gerenciamento da bacia, principalmente no município de Santana do Livramento, entre o sexo feminino e as pessoas com menor escolaridade.

A realização da pesquisa de opinião pública evidenciou o desconhecimento da gestão descentralizada dos recursos hídricos, sendo necessário a construção de um sentido de identidade da bacia. O comitê da bacia hidrográfica do rio Santa Maria pode tornar-se uma verdadeira ferramenta de articulação dos interesses da bacia e um instrumento de desenvolvimento regional integrado. Para tanto, é preciso que a sociedade assuma definitivamente a bacia hidrográfica como unidade de gestão do recurso estratégico para o desenvolvimento econômico, a água.

\section{AGRADECIMENTOS}

O presente trabalho foi desenvolvido no âmbito do projeto intitulado Simulação da Cobrança em Escala Real, financiado pelo Ministério da Ciência e Tecnologia (MCT), através do Fundo Setorial de Recursos Hídricos (CTHidro). Os autores agradecem as instituições mencionadas.

\section{REFERÊNCIAS}

BALARINE, O. F. (Org.). (2000). Projeto rio Santa Maria: a cobrança como instrumento de gestão das águas. Porto Alegre/RS: Edipucrs. $140 \mathrm{p}$.

ETHUR, A. B. M.; JACOBI, L. F.; ZANINI, R. R. (2002). Estatística: caderno didático. Santa Maria: UFSM, CCNE, Departamento de Estatística. $56 \mathrm{p}$.

EUROESTUDIOS; NOVOTECNI (2003). Estudos de Viabilidade do Programa de Recuperação e Desenvolvimento da bacia Hidrográfica do rio Santa Maria, no Estado do Rio Grande do Sul: Relatório Final. Porto Alegre: Governo da Espanha, Governo do Estado do Rio Grande do Sul, RS e Secretaria de Obras Públicas e Saneamento, RS. 
FARIA, R.C.; NOGUEIRA, J.M. Método de valoração contingente: aspectos teóricos e testes empíricos. Brasília, UnB, 1998. (Mimeogr.). 24 p.

FEPAM (2001). Enquadramento dos recursos hídricos superficiais da Bacia Hidrográfica do rio Santa Maria. Relatório. $20 \mathrm{p}$.

IBGE (2000). Censo 2000. Disponível no site do Instituto Brasileiro de Geografia e Estatística http://www.ibge.gov.br. Acesso: 29/10/2005.

IBOPE/WWF-Brasil (2005). Pesquisa de opinião pública águas no Brasil: a visão dos brasileiros. 0 que 0 brasileiro pensa sobre a conservação e o uso da água no Brasil. 37 p. Disponível no site do WWFBrasil

http://wwfbrasil.org.br/projetos/agua_10032005.htm . Acesso: 10/03/2005

PEARCE, D.W., TURNER, R.K. (1990). Economics of Natural Resources and the Environment. New York: Harvester Wheatsheaf, 1990. $378 \mathrm{p}$.

PEREIRA, D. S. P.; FORMIGA-JOHNSSON, R. M. (2005). Descentralização da gestão dos recursos hídricos em bacias nacionais no Brasil. Revista de Gestão de Água da América Latina (REGA) - Vol. 2, no. 1, p. 53-72, jan./jun.

PEREIRA, J. S.; SPEZIALI, R. (2005). Estágio Atual da implementação da Cobrança pelo uso da água no Brasil. In Anais do I Simpósio de Recursos Hídricos do Sul, Santa Maria/RS, Mar. 2005, CD-ROM, 22 p.

PROJETO MARCA D'ÁGUA (2004). Survey de membros de organismos de bacia - Relatório Preliminar - Comitê de gerenciamento da bacia hidrográfica do rio Santa Maria. Disponível no site do Projeto Marca D’Água http://www.marcadagua.org.br/bacia23.htm. Acesso: 10/01/2006

THOMAS, P.T. (2002). Proposta de uma Metodologia de Cobrança pelo Uso da Água vinculada à Escassez. Dissertação de Mestrado, COPPE/UFRJ, Rio de Janeiro/RJ, $153 \mathrm{p}$.

TURNER, R. K. (1994). Environmental economics: an elementary introduction. New York: Harvester Wheatsheaf, 1994. $327 \mathrm{p}$.

UFSM/SEMA (2004a). Desenvolvimento de ações para a implantação da outorga na Bacia do rio Santa Maria: Relatório Final. Porto Alegre: Universidade Federal de Santa Maria, Governo do Estado do Rio Grande do Sul, RS e Secretaria de Obras Públicas e Saneamento, RS.

UFSM/SEMA (2004b). Simulação da cobrança pelo uso da água para a irrigação na Bacia do rio Santa Maria: Relatório Final. Porto Alegre: Universidade Federal de Santa Maria, Governo do Estado do Rio Grande do Sul, RS e Secretaria de Obras Públicas e Saneamento, RS.
Water Resource Management And Raw Water Charges: View Of The Community In The Santa Maria River Basin, RS, Brazil

\section{ABSTRACT}

The new model of water resource management in Brazil is characterized by decentralization and the shared participation of the public power, users and society. The National System of Water Resource Management (NSWRM) is still being debated and numerous issues prevent its operationalization, the main stumbling block being the management instrument for raw water charges. The aim of the present article was to assess knowledge on water resource management, emphasizing water use charges, in the hydrographic basin of the Santa Maria River, RS, Brazil, which is predominately used for rice irrigation. According to a statistical criterion, 384 questionnaires were applied among the approximately 200,000 inhabitants with questions addressing issues on water use, the Basin Committee, and raw water charges. The survey demonstrated that the basin population is more aware of the NSWRM as compared with results obtained for the whole of Brazil. The population proved generally in favor of raw water charges for the purposes established in Brazilian legislation. The Santa Maria River Basin Committee is one of the most advanced and active in the State of Rio Grande do Sul, operating since 1994. However, in order to become a true instrument of articulation of the basin interests and local development, society must definitively consider the hydrographic basin as a management unit and the committee as a forum for advancing legal issues regarding integrated regional development.

Key words: water resource management, raw water charges, Santa Maria River Basin. 